\title{
The typological position and theoretical status of polysynthesis
}

\author{
MiCHAEL FORTESCUE \\ Department of Scandinavian Studies and Linguistics, University of \\ Copenhagen, Denmark
}

\begin{abstract}
Det har vist sig at være sværere at definere "polysyntetisk" end de andre morfologiske hovedtyper blandt verdens sprog. Af den grund har denne type været mere udsat for prokrusteanske forsøg på at tvinge den ind i den ene eller den anden teoretiske ramme. Med udgangspunkt i en liste over symptomatiske - men ikke kriterielle - træk ved polysyntetiske sprog samt eksempler på deres strukturelle forskellighed i Nordamerika og det østlige Sibirien påvises det hvordan man temmelig enkelt kan redegøre for sådanne sprog inden for den gængse Functional Grammar-model ved en mindre omfortolkning af relationen mellem modellens komponenter. Dette kontrasteres med Bakers cirkulære forsøg på at definere en "polysyntetisk parameter" inden for den Chomskyanske tradition (Baker 1996). Der fokuseres på vestgrønlandsk, koyukon (athabaskansk), tjuktji og nuuchahnulth (nootka), fire af verdens mest ekstreme eksempler på den polysyntetiske type.
\end{abstract}

\section{INTRODUCTION}

The dimension of polysynthesis has, since it was first integrated into the growing framework of morphological typology in the $19^{\text {th }}$ century by Humboldt (1988 [1827-29]), proved more difficult to define than the other major morphological 'types' among the world's languages. The actual term 'polysynthesis' had earlier been coined by Duponceau (1819) in characterizing the Indian languages of North America - Humboldt himself called it the 'incorporating' (einverleibende) type, and this is symptomatic of the problems surrounding the use of the term, since not all highly synthetic languages display (canonical) noun incorporation. In Fortescue (1994) I attempted to enumerate

Rijkhoff, Jan (ed.), Linguistic Typology, Århus: Statsbiblioteket

Tidsskrift for Sprogforskning, årgang 5, 2007

Artikel nr. 2, Fortescue, Michael, $27 \mathrm{pp}$.

http://ojs.statsbiblioteket.dk/index.php/tfs/index 
the various traits that tend to cluster together to create the appearance of a distinct polysynthetic type, namely:

(a) Noun/adjective incorporation.

(b) A large inventory of bound morphemes (but restricted number of stems).

(c) The verb a minimal clause.

(d) Pronominal markers on verbs (subject/object) and nouns (possessor).

(e) Adverbial elements integrated into verbs.

(f) Numerous morphological 'slots'.

(g) Productive morphophonemics and resultant complex allomorphy of bound and free morphemes.

(h) Non-configurational syntax.

(i) Head-marking (or double marking) type of inflection.

It is important to understand that no single polysynthetic language will necessarily have all of these traits. ${ }^{1}$

I presented in this context a mini-typology of polysynthetic morphological subtypes. Amongst them I described a 'pure incorporating' type, like Chukchi, and a 'field-affixing' (or perhaps better 'lexical affixing') type, like the Wakashan language Nuuchahnulth (Nootka), the former probably representing a newer appearance of the incorporation phenomenon than the latter. A third, 'recursive suffixing' type, like Eskimo, is not generally regarded as instantiating canonical incorporation since words in such languages, however long, may as a rule only contain one lexical morpheme (thus Comrie 1981: 42, but see Sadock 1986 for a dissenting approach) - I shall hedge this controversial issue here. This latter feature applies also to Nuuchahnulth - its 'governing' suffixes are quite parallel to the West Greenlandic verbalizing bound suffixes, as we shall see below. There are also polysynthetic languages of mixed morphological characteristics that combine more than one of the processes mentioned above. This includes the incorporating northern Athabaskan languages like Koyukon, whose templatic verbal morphology, though rich, is very rigid in terms of successive slots (only strictly inflectional ones are necessarily filled) and is not at all recursive. Koyukon verbs may nevertheless integrate almost as wide an array of incorporates as Chukchi (including heads of postpositional phrases, impossible in the latter). The relationship between 'incorporated' elements and 
corresponding independent words - ranging from exact copy via truncated version to complete absence of correlate - varies along a continuum with Chukchi and Koyukon near the first pole and Nuuchahnulth and West Greenlandic near the second.

In the present paper I shall not come much closer to defining polysynthesis as a distinct 'type', but I shall attempt to illustrate that there are better and worse ways of characterizing what is common to languages displaying the overlapping cluster of phenomena in question. I shall argue (mainly referring back to earlier work of my own) that one grammatical theory (Functional Grammar) is more satisfactory in this respect than another (Baker's version of the generative Principles and Parameters approach) since it does not rely on circular arguments determining the range of languages admitted under the rubric. A core morphosyntactic characteristic shared by many if not most languages traditionally termed 'polysynthetic' shows up egregiously on the Functional Grammar (FG) model that I endorse in terms of a special relationship between the 'Fund' and the layered structure of the clause. After discussing this, I shall make some suggestions which should prove useful in future diachronic and typological investigations of the languages concerned, namely a way of distinguishing older from newer manifestations of polysynthesis.

\section{THE CONTINUING SEARCH FOR A DEFINITION OF 'POLYSYNTHESIS'}

It is possible to define 'polysynthetic' in narrower, theory-specific terms, such that a single trait, e.g. incorporation, is regarded as criterial for its application. This is in effect what Baker (1996) does within a parametric version of generative syntax. His goal, as such, is perfectly legitimate and typifies the (belated) generative approach to integrating typological variation in theory: the attempt to show that the setting of a single superordinate 'parameter' may have farreaching consequences for other aspects of the grammar of the individual language. This is part and parcel of the search for the internal coherence of what on the surface seem like disparate phenomena, a major desideratum for functionalists and generativists alike. However, Baker's is a highly theory-biased decision, one which treats as 'polysynthetic' only a specific subset of languages with complex (mainly head-marking) morphologies that share a number of syntactic and morphological features (ones that happen to be typologically similar to those characterizing Mohawk, his starting point). In this way Chukchi 


\section{MiCHAEL FORTESCUE}

is treated as polysynthetic - by displaying noun incorporation plus obligatory 'pronominal' marking of all arguments on the head verb - while both Eskimo and Athabaskan languages (with morphologies that are in many ways even more complex) are excluded. Even Algonquian Cree Baker regards as only questionably polysynthetic since noun incorporation is not completely productive in it. There is a circularity here for which Baker has been criticized, and he himself acknowledges that he should perhaps have employed a different, more specific term (Baker 1996: 36, note 11). His procrustean method is to define a pure 'polysynthetic type' on the basis of a handful of carefully chosen languages that share certain crucial properties for his theoretical delineation of a 'polysynthesis parameter'. The fact that these features (e.g. incorporation and free word order) occur together in all of these languages is taken as proof that there is indeed a single macro-parameter that explains their association - but this is mainly because languages that don't display most of these traits have been sorted out from the start. The fact that some of his chosen languages deviate from theoretical expectations (e.g. Chukchi, which has a dependent-marked case system on NP arguments despite the head-marking nature of the 'pure' type) he explains in terms of local 'micro-parameters', which considerably undermines the universality of the endeavour. I shall return in section 4 to some specific shortcomings of this approach.

What if one were to choose 'head-marking' rather than incorporation as criterial for the type - would the picture be any clearer? The trouble is that not all languages that descriptive linguists generally agree are polysynthetic (pace Baker) are purely head-marking (Chukchi, for example, is not), and many that are predominantly head-marking are not particularly polysynthetic (cf. Nichols 1986). ${ }^{3}$

Mattissen (2003: 270) suggests that it may yet be possible to treat polysynthesis as a type, if one broadens the definition so that it comes to embrace also polysynthetic nouns as well as verbs, and equates it with the 'dependent-head' principle displayed so consistently by Nivkh (Mattissen 2003: 288f.). She sees Nivkh as differing from Chukchi on this dimension only by degree. Again, however, this runs up against the fact that not all languages linguists accept as polysynthetic obey the 'dependent-head' principle, and not all that do are polysynthetic. $^{4}$ 
So are all attempts to integrate a unitary parameter of 'polysynthesis' into a theoretical framework bound to founder in this way? Does Functional Grammar fare any better when it comes to handling this 'parameter'? In a number of articles I have attempted to show that a somewhat augmented version of the basic FG model can indeed handle polysynthetic languages in a satisfactory and unified manner. The common factor is the expanded 'Fund' of such languages which allows otherwise purely derivational processes to dip down (recursively) into 'lower' levels of the layered structure of the clause, drawing partially specified clausal structures back into the Fund for further treatment. ${ }^{5}$ This means, in effect, that syntactic properties of sentences (or accumulating operators that will effect syntactic expression) are entangled with the purely word-deriving function of the Fund. The motivation is apparent for languages displaying a high degree of head-marking on verbs: verbs are, by definition, minimal clauses in these languages, and therefore tend to behave as such, incorporating a good many clause-level arguments and grammatical morphemes in the process. Note that this accounts for a number of the features that Baker regards as criterial for polysynthesis (see his Table 11-1, pp. 498-499). ${ }^{6}$ Let me quote from the conclusion of Fortescue (1992: 128):

\begin{abstract}
I have hinted earlier that if FG is to account satisfactorily for languages with polysynthetic morphology a simple two-way distinction [...] whereby derivation is said to concern those aspects of morphology dealt with by predicate formation rules and inflection those aspects of morphology dealt with by expression rules, cannot be upheld. We shall need to envisage something more like a cline between the two (see Bybee 1985: 84f.) in order to capture what goes on in the intermediate territory which I have called 'extended derivation' [...]. Allowing for this more liberal use of the term 'derivation' has two further advantages: on the one hand, at the SoA ('state of affairs') level, one may if one wishes draw a line between 'true' derivational processes (i.e. predicate and term formation) that affect the valency of the basic predicate (or in some other way change the relationship between the predicate and its arguments), and those that do not [...]. On the other hand, at the expression rule end, one can capture much of the regularity behind the complex entanglement of derivational and inflectional morphemes in polysynthetic languages in terms of the layered structure of the predication produced by successive stages of extended derivation.
\end{abstract}

In Fortescue (1995) I discussed the case of morphological direct and indirect speech in West Greenlandic, where bound morphemes can be attached to 
whole, stereotyped utterances (in the case of direct speech) or (in the case of indirect speech) to a proposition specified for tense and (epistemic) modality, as illustrated in example sentence (1):
(1) Maalia-p miiraq irniinnaq sini-li-ssa-gunar-nirar-paa
Maalia-ERG child right.away sleep-begin-FUT-seem.to-say.that- 3SG/3SG.IND

'Maalia said that the child would probably soon fall asleep.'

Such constructions again suggest processes in the Fund 'dipping down' to already partially specified structures further down in the layered structure of the clause, and drawing them back before sending them down the 'conveyor belt' for complete inflectional specification in the final expression rule stage. The construction with -nirar- is completely productive and not at all like an ordinary word-formation process, since the suffix takes an entire proposition as its base. The additional arrow in Figure 1 (adapted from Dik 1989) illustrates the kind of 'dipping down' from the Fund to lower levels of the FG model required by sentences like this. ${ }^{7}$ 


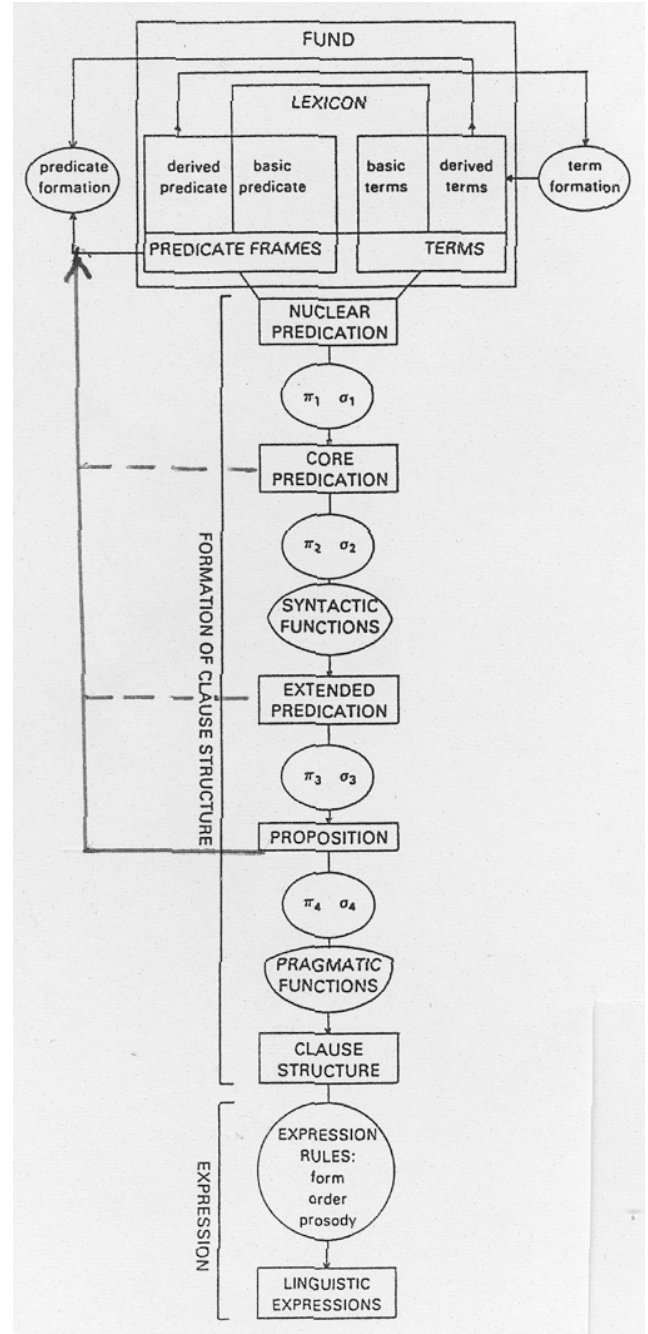

Figure 1: Overview of FG model (Dik 1989: 53)

Although Koyukon displays a templatic rather than a recursive affixing style of polysynthesis in the manner of West Greenlandic, morphemes sandwiched within the complex verb may refer also in that language to relations in the external syntax, and in the case of postpositional phrases the postposition is incorporated in the verb leaving its object stranded, as in (2) from Axelrod (1990: 181), so a satellite is drawn into a 'predicate formation' rule in the Fund. 
(2)

\author{
nelaan e-no-hughul-ghe-'ot \\ meat PP-ITER-raft-M/A-handle.compact.object
}

'He is bringing home meat by raft.' (lit. 'he is bringing a raft home with meat')

In Fortescue (1994) I assumed that Koyukon and West Greenlandic are at least as polysynthetic as those figuring among Baker's chosen set. In fact the perspective I propose also embraces the typical polysynthetic behaviour of at least one of the latter, namely Chukchi. The extreme productivity and variety of incorporation processes in Chukchi reflects the same kind of 'syntactically extended derivation' proposed for the Fund in the above-mentioned studies. In sentence (3) below (from Koptjevskaja-Tamm/Muravyova 1993: 306), for example, a satellite, -lawts- '(on the) head', appears to have been incorporated into the verb or, alternatively, it could be analysed as a possessed noun, an instance of possessor-stranding, leaving the possessor term external to the verb complex. In either case the process concerned is reasonably placed within the Fund although it makes reference to elements outside of the predicate as such.

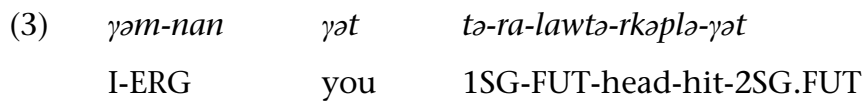

'I will hit you on the head.'

As for Nuuchahnulth, which, despite its extremely rich array of 'lexical suffixes' does not figure on Baker's list since it crucially does not involve canonical noun incorporation, it can be seen from examples like sentence (4) below from Nakayama (2003: 238) how bound morphemes within the verb complex can display independent syntactic behaviour (I shall return to this example in section 3.4.).

(4) t'i-wazaq-sańap

fall-beside-on.beach.MOM.CAUS

$\begin{array}{ll}\text { tu:cma } & \text { tl'a:qRi: } \\ \text { woman } & \text { animal.fat-DEF }\end{array}$

\author{
Zih-ak-yaq-is- $\not i$ \\ cry-DUR-has.done-on-beach-DEF
}

'It (the bird) dropped the blubber beside the crying woman.' 
In the following sections I shall present some further manifestations of polysynthetic structure in the four languages that I have chosen in order to illustrate the variety displayed by polysynthetic sub-types. In the conclusion I shall sum up my reasons for preferring the extended FG approach to Baker's parametric one in explaining both the commonalities and the differences involved and suggest that it is not really necessary to define a polysynthetic 'type' (other than as a loose prototype) in order to discuss the motivation behind the clustering of traits often found.

\section{AN ARRAY OF POLYSYNTHETIC LANGUAGES}

\subsection{West Greenlandic}

The derivational morphology of West Greenlandic (henceforth WG), like that of all Eskimo-Aleut languages, covers four major types of derivational affix (verbalizing, nominalizing, verb-extending, and noun-extending) while its inflectional paradigms cover a wide range of portmanteau combinations of mood/person/number (on verb) and case/possessor/number (on nouns). Like all the languages of the family it also contains an intermediate category of 'sentential affixes' for tense, epistemic modality, clause negation and subjective colouration positioned between stems (plus any other derivational affixes) and inflectional endings. These display suitably intermediate properties such as fixed (non-recursive) morpheme order and semantics usually associated with inflectional categories but with derivational-like optionality and the requirement of being followed by a 'true' inflection. Eskimo languages are well known for the recursive combinatoriality of their derivational morphemes, with the possibility of at least eight or so successive morphemes in a single complex word that may switch back and forth between nominal and verbal, transitive and intransitive, several times before the cumulatively compatible inflection. Only the lexical stem plus a suitable inflection (which is zero for absolutive singular nominals) is obligatory. There is also a handful of (mainly clausal) enclitics that follow the inflection. The following sentences (from Fortescue 1984) give some further idea of the possibilities: 
(5) Miki nann-un-niuti-kkuminar-tu-rujussu-u-vuq

Miki polar.bear-catch-means.for-be.good.as-PART-great-be-3SG.IND

'Miki (a dog) is really good for catching polar bears with.'

(6)
kavass-isaar-tar-puq
angi-gi-laa-gar-suar-minik
coat-wear-HAB-3SG.IND
be.big-have.as.too-a.bit-PASS.PART-big-
4SG.INSTR

'He would wear a coat rather too big for him.'

Note the typical 'modifier stranding' in (6). The scope of affixes is always transparent, increasing away from the stem quite regularly (the proposition within the scope of -nirar- in (1) has already been commented upon). The semantic effect of changing their relative order is illustrated in (7):

(7a) urnik-kusun-niqar-puq

come.to-want.to-PASS-3s.IND

'Somebody wanted to come to him.'

(7b) urnin-niqa-rusup-puq

come.to-PASS-want.to-3s.IND

'He wanted somebody to come to him.'

Although the processes illustrated above do not include canonical noun incorporation (since the verbalizing morphemes producing 'quasiincorporating' structures are bound morphemes, not independent verbs) it should be clear that the sheer degree of morphological complexity of this language makes it difficult to talk of its 'type' as other than polysynthetic.

\subsection{Chukchi}

In contrast to WG, Chukchi displays wide-spread noun incorporation and circumfixes (as well as both prefixes and suffixes) which cut across the derivational/inflectional divide. It is nevertheless easy to see what is derivational and what is inflectional, thanks to the onion-like principle of morphological structure in this language: optional derivational affixes of any kind stand closest to the stem (which is immediately preceded by any incorporated object), while obligatory inflectional ones stand outside of these, as predicted by Bybee's well- 
known generalizations (Bybee 1985). Again unlike WG, there is no intermediate 'sentential affix' category: the semantic dimensions involved are either integrated into the inflectional paradigms (notably tense) or are handled by ordinary derivational affixes. As regards the four basic types of derivational affix in WG, all are found in Chukchi (though there are far fewer of any of them). What distinguishes the morphology of the two languages most egregiously is the productive (if not to say protean) nature of (true) incorporation in Chukchi, which not only covers direct objects but also nouns in indirect object or (impersonal) subject function and nominal or verbal ('coverb') stems with a variety of adverbial adjunct functions (e.g. of goal, instrument, manner or source), which may be incorporated into verbs, plus adjectival stems, numerals and possessor nominals, interrogative pronouns, demonstrative determiners, and whole participial phrases, which may be incorporated into nouns. Nouns with incorporated adjuncts and adverbial adjuncts with secondary adverbial modification may in turn be incorporated into verbs (this is the source of the limited recursivity of the process in Chukchi). All incorporates correspond to independent nouns or adjectives, etc. (though they may be somewhat curtailed in form, notably losing any 'singulative' suffix), and virtually any nominal stem may be incorporated into any appropriate verb, and any adjectival stem into any appropriate noun. The following examples must suffice to give an impression of the possibilities ((9) is repeated from (3) above, the others are from Skorik 1961).

(8) to-tor-tay-pəlwontว-pojyz-pela-rkən

1SG-new-good-metal-lance-leave1SG.IMPF

'I leave a new good metal lance.'

(9)

$\begin{array}{lll}\text { yəm-nan } & \text { yot } & \text { tə-ra-lawtว-rkapla-yat } \\ \text { I-ERG } & \text { you } & \text { 1SG-FUT-head-hit-2SG.FUT }\end{array}$

'I will hit you on the head.'

(10) tə-lye-kory-owecwatə-rkan

1SG-very-happy-play-1SG.IMPF

'I am playing very happily.' 


\section{Michael Fortescue}

No one would doubt the 'polysynthetic' character of this language, but the very transparency of its ubiquitous incorporation processes suggests that they have not had time to develop the kind of morphological opacity (with a preponderance of bound elements) that characterizes West Greenlandic and the other two languages chosen to illustrate polysynthesis.

\subsection{Koyukon}

Koyukon displays a typical Athabaskan templatic verbal morphology, where inflectional and derivational prefixes are interdigitated with each other and with (often discontinuous) stem 'themes' in a fixed series of 'slots' (at least 28), a few obligatorily but most only optionally filled (see Kari 1986). The obligatory prefixes (inflectional except for the 'classifier'), immediately preceding the stem (or root), cover 'tense- mode', 'subject' (non- $1^{\text {st }} / 3^{\text {rd }}$ plural) and 'classifier' (a set of valency markers, including zero, now largely lexicalized with specific stems); $1^{\text {st }}$ or $3^{\text {rd }}$ person plural subject prefixes and object prefixes (all inflectional) come earlier in the word, but still among the so-called 'conjunct' prefix slots, which are intimately related to the stem. These are preceded by 'disjunct' prefix slots, which are generally more semantically peripheral to the stem than conjunct prefixes and are marked off from them by a phonological boundary. The distinction between the two categories is not simply one between derivation and inflection, however, since a number of the 'conjunct' slots are clearly derivational - both semantically and as regards optionality (e.g. the 'conative'). Some of them are obligatorily filled but quite opaque, chosen hand in hand with the stem, as part of the lexical 'theme'. There are also a handful of (clause-level) suffix slots. Rarely are there more than a handful of slots filled in a given word, as in the following typical verb-sentence (from Thompson et al. 1983: 57), where the discontinuous verbal 'theme' (the minimal lexical base of the word) consists of the root plus an opaque thematic prefix preceding the subject slot (ne ... t'aawhere the ne- may originally have meant 'eye').

(11) ne-ne-t-t'aanh

2SG-TH-1SG-see.IMPF

'I see you.'

Unlike the southern branches of Athabaskan, northern languages like Koyukon also make extensive use of noun incorporation, as in (12) and (13), with 
respectively object and inanimate subject incorporates (from Axelrod 1990: 191, 187):

to-ts'eeyh-ghee-tonh

into.water-boat-3SG.MOM-handle.long.object.PERF

'He launched the boat.'

(13) no-'etts'eeyh-ye-ghee-t-ghet

down-wind-3SG.OBJ-3SG.MOM-CAUS-long.object.move.abruptly.PERF

'The wind knocked it (e.g. a pole) down.'

This is probably an innovation since the position in the verb complex taken by incorporates is far from the stem, among the 'disjunct' prefixes. The distinction between incorporation and prefixal derivation is not watertight: many opaque derivational prefixes (common Athabaskan inheritance) may originally have been independent stems that became incorporated then partially grammaticalized. These may represent the remains of a much earlier round of incorporation than the recent productive kind. Koyukon cannot incorporate adjuncts into nouns (noun morphology in general is very simple), otherwise it has most of the possibilities found in Chukchi, although there is no multiple/recursive incorporation, and no modifier stranding as in WG. Incorporation is fairly productive but incorporates may have a slightly changed form from that of corresponding independent lexemes, and some (like lexical affixes) lack such an independent correlate altogether; moreover, not all nouns may be incorporated (Axelrod 1990: 183). It is only obligatory in certain limited circumstances, notably with verbs that incorporate an inanimate subject. Typical for all Athabaskan languages is the presence in the language of scores of (often discontinuous) 'derivational strings' - typically indicating Path or Ground or a combination of both - with inflectional consequences (for example on the choice of tense-mode prefix and of the aspectual form of the root). Some complex/discontinuous verb themes and derivational strings have an obligatory slot for an incorporate, e.g. P e-INCORP-'o 'handle P (= object of postposition $e$-) in manner indicated by incorporate', which results in the entanglement of (internal) morphology and (external) syntax, as in sentence (14), repeated from 
(2) above, where $\mathrm{M} / \mathrm{A}$ is a mode/aspect prefix. This is parallel with the applicative construction of WG (with suffix -uti- 'do with/for/because of').

(14) nelaan e-no-hughul-ghe-'ot

meat PP-ITER-raft-M/A-handle.compact.object

'He is bringing home meat by raft.' (lit. 'he is bringing a raft home with meat')

Although Koyukon lacks a category of affix intermediate between derivation and inflection like the WG sentential affixes, it could be said that productive derivational strings of path, ground, instrument and manner constitute a category intermediate between 'true' derivational prefixes (or strings) affecting the valency of the complex verb, and inflectional prefixes for tense/mode/aspect and subject/object person (in Fortescue 1992, as mentioned above, I refer to this category as 'extended derivation').

Despite the rigidity of its word order (not something typical of polysynthetic languages), the extreme complexity (and opacity) of the verbal forms of Koyukon renders it hardly controversial to call this language truly polysynthetic.

\subsection{Nuuchahnulth}

In so far as it is a suffixing-only language, with several hundred bound suffixes and only a single lexical stem/root per complex word, the morphological organization of Nuuchahnulth is rather similar to that of WG. As with other southern Wakashan languages, however, and as opposed to the other three languages under discussion, inflection is rather restricted and is expressed by clitic complexes that are typically added to the first constituent of the clause. The elements that may enter these clause-level complexes are quite diverse, namely: diminutive, intentional-causative, temporal, passive/inverse, possessive, irrealis, future, past, mood, subject pronoun, again, and habitual, in that order if more than one is chosen (all are optional). The clitic as opposed to suffixal status of some of these is still debated. ${ }^{8}$ Apart from the stem only morphological aspect is obligatory (usually suffixal but often lexically inherent), so bare 'absolutive' stems are frequent; even $1^{\text {st }} / 2^{\text {nd }}$ person subject inflections on verbs may be dropped in context (and $3^{\text {rd }}$ person singular is always zero). As regards true derivational suffixes, the most striking fact about this language is the profusion 
of 'lexical suffixes', mainly indicating dimensions of path and ground. They are an areal feature of the Northwest Coast, but correspond well semantically to Koyukon path/ground/instrumental 'derivational strings', and are quite without equivalent in WG and Chukchi. The number of suffixes per word is usually not great - an aspectual one plus one or two lexical suffixes being normal (often forming lexicalized portmanteau combinations), and there is no recursivity of the Eskimoan type. If there is more than one lexical suffix, the last one will often be one of four special 'general location' suffixes indicating 'in the house', 'outside (the house)', 'on the rocks', and 'on the beach'. Actually, there are two quite different types of suffix here: what Swadesh (1939) called 'governing' and 'restrictive' suffixes. The former correspond to the verbalizing affixes of WG and Chukchi, but note that suffixes like $-\left(k^{w}\right)$ i:t 'make' as in (15) and (16) (from Nakayama 1997: 80) are actually phrasal, attaching enclitically to any modifer. This is a kind of entanglement of syntax and morphology rather different from the modifier stranding in similar WG sentences. 'Restrictive' suffixes indicating path and ground like -it 'in the house' in (17) (from Nakayama 1997: 169) are, on the other hand, quite alien to Chukchi and WG. That sentence also illustrates another typically Wakashan phenomenon that distinguishes it from the straightforward ordering of successive affixes in WG, with scope cumulating rightwards away from the stem, namely the ubiquitous use of 'empty' (actually anaphoric pronominal) stems like $z u$ - 'it, she, him', obligatory when the semantic core of the word is a bound suffix like -qћýu:- 'together'.

(15) č́a:pac-i:t-mazuk

canoe-make-one.good.at

'Someone good at making canoes.'

(16) tlut-i:t čapac

nice-make canoe

'He made a nice canoe.'

(17) Zu-qћýu:-it-2an-i-na-?a:t-?at

PRO-together-in.the.house-INV-PAST-1PL-always-PL

'They used to live with us.' 


\section{MiCHAEL FORTESCUE}

In example (18), repeated from (4) above, it can be seen that a restrictive suffix can take its own external 'object' despite the complex word in which it appears being itself transitive and taking its own direct object. This looks like a restrictive suffix trying to act as a governing one, in competition with the stem verb: the result is an unusual compromise (but a perfectly regular one in Nuuchahnulth). ${ }^{10}$

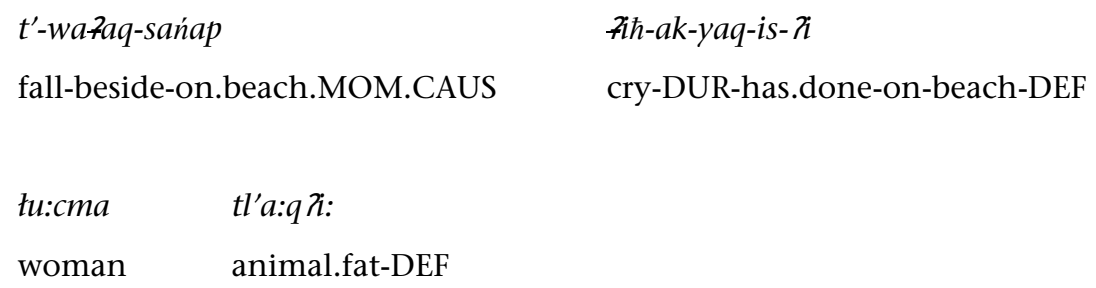

'It (the bird) dropped the blubber beside the crying woman.'

Nakayama (1997: 52-56) divides lexical suffixes in Nuuchahnulth into five types according to the semantic relationship between stem and suffix:

(a) Undergoer-predicate (with suffixes like - $\left(k^{w}\right) i: t$ 'make')

(b) Complement-higher predicate (e.g. with -'as 'go in order to')

(c) Modifier-nominal (e.g. with -małuk 'one skilled at')

(d) Numeral-classifier (e.g. with -či:t'days')

(e) Predicate-adverbial (e.g. with - ?atu 'into water')

The first three types follow the dependent-head order (with WG parallels), while the last (which may be an areal diffusion) displays the reverse (without WG parallel); case (d) - also not found in Chukchi or WG - falls semantically somewhat outside of this division, although it again displays head (noun) after dependent order.

As with WG, Nuuchahnulth displays certain traits not typical of 'canonical' polysynthetic languages (enough to eliminate it from the category according to Baker), in particular its lack of 'true' incorporation plus the laxity of (clitic) subject marking on the verb. Nevertheless, there are few linguists - apart from Baker - who would not want to characterize this language as a priori polysynthetic. 


\section{A SPECIFIC DIMENSION: THE INCORPORATION OF NON-OBJECTS}

At this point I should like to examine in more detail a single dimension of variation that leads nowhere at all within Baker's parametric account, but which makes sense within the extended FG model, namely the incorporation of elements other than direct object nouns in verbs. Baker predictably dismisses this as a matter of non-syntactic, lexical compounding: according to his definition 'real' incorporation is syntactic and solely concerns the incorporation of direct object nouns into their verbal heads (Baker 1996: 295). Let me just follow this up by illustrating the incorporation of non-objects in one of Baker's 'polysynthetic' languages, Chukchi, and in one of his non-polysynthetic (but highly head-marking) languages, Koyukon (for further details see Fortescue 2002).

Incorporated subjects in Chukchi, as in (19), are much less common than incorporated objects, always involving subjects low in animacy, but this is partly because in many cases such non-agentive incorporated subjects can be analysed as in adverbial function rather, as in sentences (20) and (21):

(19) terk-amecat- $\gamma$ ?e

sun-go.down-3s.AOR

'The sun went down.'

(20) onne-tke-rkan

fish-smell-3s.PRES

'There is a smell of fish.'

(21) no-lola-kawral 7at-qen

IMPF-eye-go.round-3s.IMPF

'His eyes are going round (in his head).' (idiom meaning 'he is so tired')

The following sentences illustrate the incorporation into head verbs of verbal stems in adverbial function: 
(22)

katyantə-pkerə-k

run-arrive-INF

'To arrive running.'

(23)

ta-micyireta-lqatว-rkan

1s-work-go-1s.PRES

'I am going to work.'

Note that in (22) we not only find an incorporating construction that is supposed to be mere 'lexical compounding' (though it is quite productive in Chukchi), we also find something that a polysynthetic language should not have according to Baker, namely an infinitive form. Baker actually points out this discrepancy in a footnote to his Table 11-1, but he tries to explain it away as not really an infinitive because the suffix concerned is the same as the locative case marker and therefore such forms can be analyzed as nouns or as predicates in a light verb construction (though there is absolutely nothing nominal about the two verb morphemes themselves here). One supposes that the only reason Chukchi - with its largely dependent-marking morphology - is allowed by Baker to stay in good polysynthetic company is the extreme productivity of its noun incorporation. ${ }^{11}$

As regards the incorporation of non-objects in Koyukon, this is limited to impersonal subjects/forces of nature, i.e. to subjects low on the scale of potential agenthood, where the construction is obligatory (Axelrod 1990: 184). In (24a) the non-incorporating construction would imply inappropriate control/deliberateness on the part of the subject (compare 24b, where the same verb is used with an ordinary non-incorporated human subject). In sentence (12) in section 3.3. a transitive example has already been seen.

(24a) nee-to-nee-yo

up.to.a.point-water-M/A-go

'The water stopped rising.' 
(24b) John nee-nee-yo

John up.to.a.point-M/A-go

'John went up to a point (and stopped).'

Example (13) in 3.3. illustrated the incorporation of a noun in other than subject/object function, and (25) below illustrates the incorporation of a property-denoting stative verb into the matrix verb in adverbial function:

\section{(25) b-e-no-tset-'ee-de-tlaakk}

3s-PP-ITER-wet-M/A-CL-be (wet.object) ${ }^{12}$

'He came home soaking wet.'

Whereas these phenomena would require separate explanations for Baker (respectively one for a polysynthetic and one for a non-polysynthetic language), the 'extended derivation' perspective within FG can offer a unified explanation covering both types of language. It is again a matter of predicate formation rules 'dipping down' into the layered structure of the clause from the Fund, with the possible consequence of the entanglement of syntax and morphology. The point is that predicate-formation rules can display various degrees of 'extension', ranging from canonical word-formation (no extension out of the Fund) to productive processes with various kinds of syntactic consequences outside of the complex word (e.g. the case-marking of stranded modifiers in WG or the addition of a restrictive suffixes own external 'object' in Nuuchahnulth). In both the languages treated above the motivation for subject-incorporation is low animacy/agency, not typical of subject arguments (independent subjects require at least some potential degree of control). The process is unlike ordinary derivational word-formation (limited to the non-clausal word) in its productivity. In fact it is obligatory in Koyukon, as explained above, a language where animacy concerns are prominent in the grammar. The incorporation of adverbial satellites is a common phenomenon in head-marking languages (and Chukchi is head-marking in its verbal morphology at least). Incorporation of adjectival modifiers, as in Chukchi, is less so, but is on the other hand not limited to head-marking languages (neighbouring Yukagir, even more dependent-marking than Chukchi, displays it too). Adjunct incorporation is in general more like canonical word-formation, less 'syntax-like' than object or 
subject incorporation, but it is nevertheless odd that it is the 'true' polysynthetic language Chukchi that displays it to such a high degree and not nonpolysynthetic (acc. Baker) Koyukon (or West Greenlandic), which does not have it at all. Baker's 'polysynthetic parameter' has nothing to offer here in the way of explanation.

\section{CONCLUSIONS}

Despite the great variety in structure that we have seen in the four polysynthetic languages chosen for this paper, there appears to be a common thread after all I shall return to this in a moment. Most of the significant differences between sub-types are a function of different historical developments, all perhaps fuelled by increasing head-markedness (at least in the verbal complex), along a grammaticalization pathway leading from lexical stem $>$ incorporate $>$ lexical affix > grammatical affix. By the process of 'layering', vestiges of several stages may remain in the same language. In WG we may distinguish between those of its derivational affixes that are still lexically 'heavy' enough to be regarded as lexical affixes and those - for instance its many aspectual affixes - which can be considered 'grammatical' (though not yet inflectional). Virtually all trace of the supposed lexical sources of its derivational affixes has been lost, however. The only analogue of productive incorporation is in its bound verbalizing affixes corresponding to Nuuchahnulth 'governing' suffixes. The latter language lies close to WG in this respect, though it has not developed anything like the variety of 'grammatical' affixes that WG has - much of its aspectual system, for instance, involves reduplication, a process falling outside the grammaticalization pathway in question, and all clause-level grammatical morphemes are clitics rather (from adverbials of various sorts and amalgams of modal particles and pronouns). In Chukchi the path has evidently been shorter than in either of these languages, with fully productive incorporation of nominal and adjectival stems not yet having produced lexical affixes (though some incorporated - or serialized - verbs and/or adverbials have indeed produced derivational affixes). Koyukon falls somewhere in between, depending on how one analyses those of its 'derivational strings' that contain core elements relatable to independent words, i.e. as lexical affixes or not; but this language clearly displays different historical layers of prefixation, with the older - conjunct - prefixes almost completely opaque as regards lexical source and phonologically worn down to a 
minimum, while a newer, rather productive round of incorporation of lexical items has filled historically later 'disjunct' slots.

The question arises now as to whether we can distinguish 'newer' from 'older' polysynthetic languages generally. The facts presented above - which could be supplemented with data from a great many more polysynthetic languages of North America - suggest a number of traits that are symptomatic for polysynthesis in a given language being 'old' as opposed to 'new'. Those pointing towards older polysynthesis include:

(a) Few if any lexical sources of derivational affixes to be found.

(b) No independent stress (or other individualizing prosodic marking) on incorporated morphemes.

(c) Entangled ordering of derivational and inflectional morphemes.

(d) Evidence of successive historical layering of affixes, with fossilization.

Those indicative of newer polysynthesis include:

(a) Lexical sources of derivational affixes transparent.

(b) Residual stress on incorporated or serialized stems.

(c) Strict adhesion to Bybee's morpheme-ordering generalizations (derivation affixes closer to stem than inflection).

(d) Productivity of incorporation or morphological verb serialization. ${ }^{13}$

When these criteria are applied to the four languages discussed in this study, it should be clear that Chukchi typifies relatively new polysynthesis and Nuuchahnulth very old polysynthesis, with West Greenlandic and Koyukon closer to the latter pole.

To the symptomatic traits listed above could be added a further one for the interaction of syntax and morphology, but this is common to both old and new polysynthesis, as we have seen in our comparison of Chukchi and the other languages above. It could well represent the bottom line for what holds polysynthesis together as something approximating a common type (beyond sheer morpheme-per-word count). From the extended FG perspective, polysynthetic languages are different from other languages in the degree to which their predicate-formation rules may extend into and interact with the 


\section{Michael Fortescue}

layered structure of the clause as a whole, and that would account for this trait (or dimension of variation).

This approach, it seems to me, provides a more fruitful answer to the question as to what polysynthetic languages have in common than Baker's proposal of a highly abstract 'polysynthetic parameter', which lacks motivation other than theory-internal consistency. ${ }^{14}$ All that Baker's Principles and Parameters approach can predict is that if a language has syntactic noun incorporation (defined theory-internally), then it also should have the other cluster of traits he associates with the purported 'polysynthetic parameter'. This simply does not hold water empirically. At most it circumscribes a 'Mohawk-like' cluster of traits found in a certain number of languages. The FG solution I have sketched, on the other hand, predicts that if a language has predicate formation rules that take whole propositional structures as their input, it will also have such rules taking units lower in the layered structure of the clause, in particular unelaborated nuclear predications (predications extended for aspect lie in between). Specifically as regards noun incorporation (another kind of predicate formation rule), languages which allow modifier stranding will, it is predicted, also have structures without such stranding, but not the other way round. In both cases the less common kind of structure (typifying highly polysynthetic languages) involves specific kinds of entanglement of morphology and syntax, expressed as varying input conditions to predicate formation rules in FG. Although these predictions hold up, as far as I can see, the approach can not be used to define a precise cutoff point where languages of a polysynthetic type start - it cannot, for example, decisively solve the problem of classifying languages such as the Wakashan ones where clitics blur the picture.

However, the approach I have presented at least reveals a common motivation for what appears to hold these highly synthetic languages together as an approximate or 'prototypical' type, namely the elaborate derivational potential of their verbal morphology. Derivational processes in these languages may apply not only to word stems but to whole phrases treated as stems despite any external manifestations of their own syntactic dependencies. Inflected verbs are minimal sentences in these languages, thus it is no surprise that the watertight distinction between the syntactic domains of words and sentences is blurred in them. 
Much remains to be done, however, in fleshing out the diachronic and areal consequences of the kind of 'extension of the Fund' analysis I have proposed. How rapidly could it occur? How rapidly diffuse? What might trigger or facilitate the 'crossing of the Rubicon' from ordinary synthesis? What might restrain it? Detailed empirical work from as broad a range of languages as possible must be brought to bear on these questions, and squabbling about the exact boundary line demarcating the purported language 'type' involved may hinder this work more than it furthers it.

\begin{tabular}{ll} 
ABBREVIATIONS \\
AOR & aorist \\
CAUS & causative (classifier) \\
COM & comitative \\
DEF & definite \\
DUR & durative \\
ERG & ergative \\
FUT & future \\
HAB & habitual \\
IMPF & imperfective \\
IND & indicative \\
INF & infinitive \\
INV & inverse \\
ITER & iterative \\
MOM & momentaneous (MOM.CAUS momentaneous causative) \\
PART & participial \\
PASS & passive \\
PASS.PART & passive participial \\
PAST & past \\
PERF & perfective \\
PL & plural \\
PP & postposition \\
PRES & present \\
PRO & pronominal \\
SG & singular \\
\hline
\end{tabular}




\section{MiCHAEL FORTESCUE}

\section{REFERENCES}

Axelrod, Melissa (1990), "Incorporation in Koyukon Athapaskan", International Journal of American Linguistics, 56/2 (1990), pp. 179-194.

Baker, Mark C. (1996), The Polysynthesis Parameter, New York/Oxford: Oxford University Press.

Bybee, Joan L. (1985), Morphology, Amsterdam/Philadelphia: John Benjamins.

Comrie, Bernard (1981), Language Universals and Linguistic Typology, Oxford: Basil Blackwood.

Dahl, Östen (2004), The Growth and Maintenance of Linguistic Complexity, Amsterdam/Philadelphia: John Benjamins.

Dik, Simon (1989), The Theory of Functional Grammar, Part 1, Dordrecht: Foris.

Drossard, Werner (2002), "Ket As a Polysynthetic Language, With Special Reference to Complex Verbs", in: Evans, Nicholas, Hans-Jürgen Sasse (eds.) (2002), Problems of Polysynthesis, Berlin: Akademie Verlag, pp. 223-256.

Duponceau, Peter S. (1819), "Report of the Corresponding Secretary to the Committee of His Progress in the Investigation of the Language of the American Indians", Transactions of the Historical and Literary Committee, 1.

Evans, Nicholas, Hans-Jürgen Sasse (eds.) (2002), Problems of Polysynthesis, Berlin: Akademie Verlag.

Fortescue, Michael (1984), West Greenlandic, Beckenham: Croom Helm.

Fortescue, Michael (1992), “Aspect and Superaspect in Koyukon: an Application of the Functional Grammar Model to a Polysynthetic Language", in: Fortescue, Michael, Peter Harder, Lars Kristoffersen (eds.) (1992), Layered Structure and Reference in a Functional Perspective, Amsterdam/Philadelphia: John Benjamins, pp. 99-141.

Fortescue, Michael (1994), "Polysynthetic Morphology", in: Asher, R. E. et al. (chief editor) (1994), Encyclopedia of Language and Linguistics, Oxford: Pergamon Press, pp. 2601-2602.

Fortescue, Michael (1995), "Morphological Versus Syntactic Direct and Indirect Speech in West Greenlandic Eskimo", in: Schousboe, Steen (ed.) (1995) Embedding in Functional Grammar, Publications of Department of English, 20, Copenhagen: University of Copenhagen, pp. 7-33.

Fortescue, Michael (2002), "Incorporation in Chukchi Compared With Koyukon and Cree", in: Nedergaard Thomsen, Ole Michael Herslund (eds.) (2002), Complex Predicates and Incorporation, a Functional Perspective, Traveaux du Cercle Linguistique de Copenhague XXXII, Copenhagen: Reitzel, pp. 48-66.

Humboldt, Wilhelm von (1988), On Language: The Diversity of Human Language Structure and Its Influence on the Mental Development of Mankind, Cambridge: Cambridge University Press (original German version 1827-29). 
Kari, James (1986), “Affix Positions and Zones in the Athabaskan Verb Complex: Ahtna and Navajo", International Journal of American Linguistics, 55/4 (1986), pp. 424-454.

Koptjevskaja-Tamm, Maria, Irina Muravyova (1993), “Alutor Causatives, Noun Incorporation, and the Mirror Principle", in: Comrie, Bernhard, Marie Polinsky (eds.) (1993), Causatives and Transitivity, Amsterdam/Philadelphia: John Benjamins, pp. 287-313.

Kristoffersen, Lars (1992), "Derivation and Inflection in a Functional Grammar of West Greenlandic", in: Fortescue, Michael, Peter Harder, Lars Kristoffersen (eds.) (1992), Layered Structure and Reference in a Functional Perspective, Amsterdam/Philadelphia: John Benjamins, pp. 143-171.

Mattissen, Johanna (2003), Dependent-Head Synthesis in Nivkh, Amsterdam/Philadelphia: John Benjamins.

Nakayama, Toshihide (1997), Discourse-Pragmatic Dynamism in Nuu-chah-nulth (Nootka) Morphosyntax, Ph.D. dissertation, University of California at Santa Barbara.

Nakayama, Toshihide (2003), Caroline Little's Nuu-chah-nulth (Ahousaht) Texts With Grammatical Analysis, Endangered Languages of the Pacific Rim A2-027, Suita: Faculty of Informatics, Osaka Gakuin University.

Nichols, Johanna (1986), "Head-Marking and Dependent-Marking Grammar", Language, 62 (1986), pp. 56-119.

Sadock, Jerold (1986), "Some Notes on Noun Incorporation", Language, 62 (1986), pp. 19-31.

Skorik, P. J. (1961), Grammatika Čukotskogo jazyka, č. 1, Moskva/Leningrad: Akademija nauk.

Swadesh, Morris (1939), "Nootka Internal Syntax", International Journal of American Linguistics, 9/2-4 (1939), pp. 78-102.

Thompson, Chad, Melissa Axelrod, Eliza Jones (1983), Han zaditL'ee, Scope and Sequence, Yukon-Koyukuk School District Koyukon Language Curriculum, Nenana, Alaska.

\section{NOTES}

1 Compare the tentative definition in Evans and Sasse (2002: 3f.): "Essentially, then, a prototypical polysynthetic language is one in which it is possible, in a single word, to use processes of morphological composition to encode information about both the predicate and all its arguments, for all major clause types [...] to a level of specificity allowing this word to serve alone as a free-standing utterance without reliance on context." They leave open the possibility that languages without incorporation and/or without agreement affixes could also be considered polysynthetic, and point out, quite rightly, that any more specific cluster of criteria such as Baker's is circular unless it can be substantiated empirically from a broader sample of the world's languages.

2 The component of Dik's model that embraces the lexicon and includes all derived terms and predicates.

3 Nichols (1986: 88) sees polysynthetic languages as deriving from more moderately head-marking languages through more and more independent clausal elements being 


\section{MichaEL FORTESCUE}

drawn into the verb complex (by the 'head-ward migration of morphemes'). This suggests that 'polysynthesis' is for her an extreme variety of head-marking.

4 The fact that there is no marking of subjects on verbs in Nivkh would seem to make it somewhat less than prototypical as a polysynthetic language, in fact - but note that Wakashan languages too share this feature to some degree (with moveable clitic subject markers).

5 Kristoffersen (1992: 152) reached a similar conclusion as regards West Greenlandic, suggesting the term 'proposition-formation' rule for the kind of construction illustrated in (2) below. For those unfamiliar with the FG terminology, it should be explained that the Fund is that component of Dik's (1989) model that contains not only the Lexicon with its basic predicates and terms (potential referring expressions) but also predicate-formation and term-formation rules that convert them into derived predicates and terms. It is the output of the Fund (core predications consisting of the predicate frames of verbs filled by appropriate term arguments) that acts as input to the successive layering of operators and satellites on the way to the delivery of a semantically fully specified clause structure to the expression rules, where linearization and morphological spell-out occurs. One of the higher levels of elaboration of the clause is the 'proposition' (prior to pragmatic/illocutionary specification). These 'higher' levels are generally schematized as lying below the Fund (as on Figure 1), hence my use of the expression 'dipping down'.

6 These include, beside syntactic noun incorporation, object agreement, free pro-drop, free word order, no NP reflexive, no true quantifiers or demonstratives, nouns agreeing with possessor, and no infinitive. Baker admits slight deviations from the complete list in certain of the languages he regards as polysynthetic, but attributes these to areal influence if not to 'micro-parameters', not further specified.

7 This should be understood in the following way: the 'proposition' miiraq irniinnaq sinili-ssa-gunar- (still uninflected for obligatory person/number/mood) is 'pulled back' into the Fund before it has reached full specification as an illocutionary 'clause', and cycled through a predicate-formation rule which attaches bound verbal morpheme -nirar- and the ergative subject which that morpheme sub-categorizes for before being sent on for full specification and expression. Other, more typical 'verb-extending' affixes such as -juma 'want to' dip down only as far as the level of the 'extended predication' (and some 'verb modifiers' just to the 'core predication'), as indicated by the broken lines on Figure 1. An example given by Kristoffersen (1992: 159) is pingasunngurnikkut iga- saruma-vunga (on.Wednesdays cook-HAB-want.to-1s.INDIC) 'I want to do the cooking on Wednesdays', with both the external adverbial 'on Wednesdays' and the habitual marker -sar- within the scope of -(j)uma- (Kristoffersen argues convincingly that the affix expresses a so-called $\pi_{2}$ operator).

8 This is a matter of some theoretical importance, since, as Nichols (1986: 93) points out, whether Wakashan languages count as predominantly 'head.marking' or as 'dependent-marking' depends on whether clitics are taken as part of the verb complex or not.

9 Furthermore, the distinction between the nominal and (ad)verbal function of such affixes is largely blurred (out of context), unlike the clear part-of-speech (and transitivity) status of all derivational affixes in WG and Chukchi. Lexical suffixes may refer either to location or to movement, to an attribute or to an exponent of that attribute, to an action or to someone that does that action (or a place where it is done). This is part and parcel of the general - and notorious - lack of clear-cut parts of speech distinctions in the Wakashan languages.

10 That the transitive portmanteau morpheme -sańap of caused momentaneous (or perfective) action on the beach applies to the action expressed by the stem and not to the lexical suffix -wazaq can be seen by comparing the following form found a little later in the same text: t'i-ńi-sańap (fall-down.slope-on.beach.MOM.CAUS) '(They) threw it out (down) on the beach.' 
THE TYPOLOGICAL POSITION AND THEORETICAL STATUS OF POLYSYNTHESIS

11 Even though the most productive form of incorporation in Chukchi is actually adjunct incorporation. This has much to do with the widespread use of circumfixes in its inflectional and derivational morphology, as in ra-tot-r7asqə-ma (COM-new-sword$\mathrm{COM}$ ) 'with a new knife', where the comitative case requires the incorporation of any modifier of the head noun.

12 ' $\mathrm{CL}$ ' is a so-called classifier, an obligatory voice prefixed to a given verbal stem. 'ITER' for 'iterative aspect' refers to returning to a starting point, and the 'classificatory' verb stem tlaakk usually refers to a wet object lying around somewhere.

13 It should be added concerning trait (c) that Bybee's generalizations can be broken by various diachronic processes, for example when a former auxiliary coalesces to a main verb. As regards trait (d), compare Drossard (2002: 228) concerning serial verb constructions in polysynthetic Ket: this is obviously not a phenomenon limited to areas of South Asia, Papua and Africa, where such constructions are widespread.

14 It is also compatible with Sadock's 'autolexical' approach, which focuses upon mismatches between morphology and syntax, and at least provides the possibility of semantic/pragmatic motivation for such mismatches, but time and space precludes drawing yet another theoretical framework into my argument here. 